\title{
Palaeontologia Electronica in an increasingly open-access world
}

\author{
Julien Louys
}

When Palaeontologia Electronica (PE) published its first issue in 1998 (the first electronic palaeontological peer-reviewed journal), the primary goal of the journal was to harness the incredible technological potential of electronic publishing: speeding up the process of technical communication and making the emergent web-based technologies available to palaeontologists (MacLeod and Patterson, 1998). Our journal is now very much on the apogee of electronic publishing, although rapid evolution of the nature of scientific dissemination outside the traditional avenues of scholarly publishing means that we cannot afford to stagnate in this pursuit. It is therefore fitting that one of the big changes PE has experienced over the last few years has been the addition of several new editorial board members, all of whom are early to midcareer palaeontologists who have grown up with an innate appreciation of the internet's technological potential, allowing us to readily adapt to the very different cyberspace of today's World Wide Web.

In 2015 the journal no longer faces the challenge of academic acceptance of electronic publication. This form of publication has now been firmly accepted by the vast majority of working scientists, and moving forward PE must instead look at the new challenges facing professional researchers, and particularly for PE, non-professional readers and contributors. In the $21^{\text {st }}$ century, no other issue has shaken the academic publication institution more than the rise of, and push for, open-access (OA). In 2011, approximately $17 \%$ of all articles were published as open-access (Laskoo and Björk, 2012), and this number is set to rise dramatically. The open-access movement is firmly rooted in the philosophy that publically funded research should be made free and available to all. In a world of different funding models of open-access, and different levels of open-access, Palaeontologia Electronica wears its OA credentials on its sleeve and has always done so.

The increased pressure for $O A$ has driven many traditional for-profit scholarly publishers to offer OA articles through an article processing charge, with most subscription organisations now publishing hybrid journals, giving the authors the choice to make their articles OA for a fee. Several publishing groups have also launched OA only journals funded through article processing fees. Article processing charges across OA journals can range from hundreds to thousands of dollars (Solomon and Björk, 2012). Entirely thanks to the support of our sponsoring societies, The Palaeontological Association, The Society of Vertebrate Paleontology, and The Paleontological Society, as well as the Western Interior Paleontological Society, PE maintains a completely free publication process for both authors and readers. The claim that higher processing charges leads to greater journal impact and prestige does not always hold

Keywords: open-access; creative commons

Julien Louys. Department of Archaeology and Natural History, School of Culture, History, and Languages, ANU College of Asia and the Pacific, The Australian National University, Canberra ACT 2601, Australia julien.louys@anu.edu.au 
(van Noorden, 2013), with many high prestige journals entirely free for readers and authors (West et al., 2014). Of course, journal prestige is difficult if not impossible to measure, and some OA advocacy organisations eschew such measures entirely (e.g., The Directory of Open Access Publishers: https://doaj.org/publishers, accessed 22 June 2015).

Nevertheless, and even though it is becoming widely acknowledged that using journal prestige measures constitutes bad practice, a journal's perceived or measured prestige continues to be an important part of submission and reading strategies (Brembs et al., 2013). It also impacts, whether consciously or not, grant applications and promotion decisions. This is unlikely to change soon, and until it does, a journal's prestige, whether measured by the universally accepted Thomas Reuters Impact Factor, or widely used websites such as Google Scholar, will continue to impact both the number and the quality of submissions. In this context, it is encouraging to note that PE's Impact Factor has been rising steadily since first issued in 2005; and amongst completely free, OA geoscience journals PE ranks fourth, and is first amongst palaeontology-specific journals under the same metrics (http://www.eigenfactor.org/openaccess/). However meaningful such statistics may be, our rapidly increasing number of published articles per issue as well as their subject diversity speaks volumes of the good reputation that PE enjoys amongst the wider palaeontological, and indeed scientific, community as an OA publication.

The large increase in submissions and publications over the last few years has seen PE's editorial board grow in equal measure. Since 2013, we have added several new handling and style editors, as well as seen some turnover in existing roles. Andrew Bush, Carolin Haug, and Brian Beatty joined the editorial board at the end of 2014 as new Handling Editors, and Camille Grohe, Karen Black, and Kenny Travouillon joined at the same time as new Style Editors. In 2015 Kerin Claeson and Daniel Hembee joined as Handling Editors, and Yasuyuki Nakamura joined as Style Editor. Stephen Dornbos has replaced Roy Plotnick as Commentary Editor, and Christian Kammerer has replaced Dena Smith as our Reviews Editor. In keeping with the incredible diversity of submissions and their countries of origins, our new editors hail from all over the world and work on everything from trace fossils to fossil marsupials. We have also created the new position of Blog and Publication Relations Editor to oversee our social media and online presence, with Amy Atwater taking on this role. Complementing our editors are a dedicated team of translators including Ashraf M.T. Elewa, Kenny J. Travouillon, Antoine Souron, Eva Gebauer, Enrique Peñalver Mollá, and Diana Elizabeth Fernández, who translate article abstracts in an effort to make the research published at PE as widely available as possible.

Perhaps our biggest editorial change, however, comes with the rotation off the editorial board of P. David Polly, who will be taking up the presidency of The Society of Vertebrate Paleontology (SVP), one of our sponsorship organisations. David has been with Palaeontologia Electronica since it began in 1998 as a founding board member and since 2003 has worked as Executive Editor. During his time with PE, David helped bring the journal from a novel experiment in palaeontological academic publishing to the widely respected international journal it is now. David published several papers with PE (Polly, 2004; Polly and MacLeod, 2008; Polly et al., 2011) in addition to contributing editorial direction and vision. It is in large part because of his incredible efforts in promoting and supporting the journal that PE now enjoys such a high impact factor and commands such respect in the OA publishing world. We wish David all the best with SVP; he will be sorely missed at PE, and as incoming Executive Editor I certainly have big shoes to fill.

Going forward, PE will seek to maintain excellence in electronic publishing and to stay at the vanguard of, and promote, free OA publication. To that end, it is a pleasure to announce that The Society of Vertebrate Paleontology is surrendering all copyright of their PE articles, in favour of making them accessible under CC-BY protocols. This means that effective immediately, copyright permissions do not need to be sought from SVP for reproduction requests for any current or future $P E$ publications where SVP has been assigned copyright provided the original author and source are credited (https://creativecommons.org/licenses/by/ 4.0/). In acknowledgment that article level metrics are much more indicative of the quality of research than the prestige of any given journal, and given that Google Scholar is fast becoming one of the primary search and metric tools for scholarly publications, we are currently working on making all our articles fully and appropriately indexed with this website. PE remains fully committed to OA principals, and will continue to explore ways of making all our articles as searchable, interactive, and use- 
ful as possible for readers and authors in an increasingly open-access publishing environment.

\section{REFERENCES}

Brembs, B., Button, K., and Munafò, M. 2013. Deep impact: unintended consequences of journal rank. Frontiers in Human Neuroscience, 7:291.

Laskoo, M. and Björk, B. 2012. Anatomy of open access publishing: a study of longitudinal development and internal structure. BMC Medicine, 10:124.

MacLeod, N. and Patterson, R.T. 1998. The role and the promise of electronic publishing in paleontology. Palaeontologia Electronica, Editorial 1.1; palaeoelectronica.org/content/the-role-and-the-promise-ofelectronic-publishing-in-paleontology.

Polly, P.D. 2004. On the simulation of the evolution of morphological shape: multivariate shape under selection and drift. Palaeontologia Electronica, 7A:28; palaeo-electronica.org/paleo/2004_2/evo/ issue2_04.htm.
Polly, P.D., Killick, L., and Ruddy, M.. 2011. Using leftright asymmetry to estimate non-genetic variation in vole teeth (Arvicolinae, Muridae, Rodentia). Palaeontologia Electronica, 41A:12; palaeo-electronica.org/ 2011_3/24_polly/index.html.

Polly, P.D. and MacLeod, N. 2008. Locomotion in fossil Carnivora: an application of Eigensurface analysis for morphometric comparison of 3D surface. Palaeontologia Electronica, 10A:13; palaeo-electronica.org/2008_2/135/index.html.

Solomon, D.J. and Björk, B. 2012. A study of open access journals using article processing charges. Journal of the American Society for Information Science and Technology, 63:1485-1495.

van Noorden, R. 2013. The true cost of scientific publishing. Nature, 495:426-429.

West, J.D., Bergstrom, T., and Bergstrom, C.T. 2014. Cost effectiveness of open access publications. Economic Enquiry, 52:1315-1321. 